\title{
Invasive breast carcinoma with granulomatous response and deposition of unusual amyloid
}

\author{
D Santini, G Pasquinelli, M Alberghini, G N Martinelli, M Taffurelli
}

\begin{abstract}
Aims: To report an unusual case of invasive breast ductal carcinoma associated with non-caseating epithelioid granuloma and unusual deposition of amyloid. Methods: Formalin fixed, paraffin wax embedded tissue from breast and lymph nodes were stained with a variety of methods. Representative tissue fragments were sampled and fixed in $2.5 \%$ buffered glutaraldehyde, postfixed in $1 \%$ osmium tetroxide, dehydrated and embedded in Araldite. Thin sections were viewed under a Phillips 400T transmission electron microscope.

Results: Multinucleated giant Langhans' cells were found in the granulomatas tissue in both breast carcinoma and metastatic axillary lymph node carcinoma. Electron microscopic examination showed "tubular'" amyloid deposition intermingled with invasive carcinoma and granuloma. "Tubular amyloid" was characterised by a mesh of non-branching curving fibrils with hollow profiles. These tended to be located in the cell membranes.

Conclusion: The presence of an epithelioid granulomatous reaction and deposition of "tubular" amyloid in an invasive breast carcinoma could be related to an abnormal immunological response.
\end{abstract}

( Clin Pathol 1992;45:885-888)

Granulomatous disease of the breast is uncommon as is the association between breast cancer and host granulomatous reaction. ${ }^{1}$ The presence of a solitary amyloid deposition within mammary tissue has rarely been described. ${ }^{2-5}$

We report a case of invasive breast ductal carcinoma showing non-caseating granulomas, associated with deposition of a peculiar amyloid type. As far as we know, these patterns, present both in the carcinoma and metastatic axillary lymph nodes, have not been reported before.

\section{Case report}

A 75 year old woman had a subareolar mass in her left breast. Mammograms showed up the presence of a suspicious looking subareolar lump that was clinically associated with axillary lymphoadenopathy. The patient underwent radical modified mastectomy. The breast tissue contained a $25 \mathrm{~cm}$ whitish gritty nodule. Pos- itivity for oestrogen ( $14 \mathrm{fm} / \mathrm{mg}$ protein) and progesterone ( $14 \mathrm{fm} / \mathrm{mg}$ protein) receptors was detected using an enzyme immunoassay technique. There was no evidence of either localised or widespread infectious disease. All routine serological tests were negative for infectious disease. The patient was alive and well, without recurrence, six months after her mastectomy.

\section{Methods}

Sections of formalin fixed and paraffin wax embedded breast and lymph node tissues were stained according to the following methods: haematoxylin and eosin; periodic acid Schiff (PAS) with and without diastase digestion; alcian blue-PAS; von Gieson elastic fibre; Ziehl-Nielsen; and Congo red. An immunohistochemical investigation for L26 (Dako, 1 in 100), UHCL 1 (Dako, 1 in 100), $\kappa$ light chain (Dako, 1 in 20), $\lambda$ light chain (Dako, 1 in 200), anti-macrophage (Dako, 1 in 100), $\beta 2$ microglobulin (Dako, 1 in 1000) and amyloidP-component (Dako, 1 in 80 ) was performed using the peroxidase-antiperoxidase (PAP) technique. For transmission electron microscopy, representative tissue fragments were sampled and fixed in $2.5 \%$ buffered glutaraldehyde, postfixed in $1 \%$ osmium tetroxide, dehydrated, and embedded in Araldite. Thin sections were stained with uranyl acetate and lead citrate and viewed under a Philips 400T transmission electron microscope.

\section{Pathological findings}

According to the WHO, ${ }^{6}$ the neoplasm was histologically classified as invasive ductal carcinoma (NOS) grade II. Light microscopical examination showed that the tumour cells were mainly arranged in cords and nests, with scanty formation of ductal structures and fibrotic stroma. Necrosis and elastosis were absent. A diffuse granulomatous reaction with multinucleated giant cells was admixed with the invasive carcinoma (fig 1). The giant elements, exhibiting peripherally located nuclei, resembled Langhans' giant cells. Asteroid or Schaumann bodies were not observed. Lymphocytic infiltration was also associated with the granulomas. Granulomatous giant cell reaction was also present in two out of 20 lymph nodes containing metastatic carcinoma and was associated with neoplastic cells. The non-metastatic axillary lymph node tissue lacked any granulomatous response. No acid fast bacilli or fungi were detected. Congo red 
Figure 1 Epithelioid cell granuloma with Langhans' type giant cells intermixed with invasive ductal carcinoma (haematoxylin and eosin).

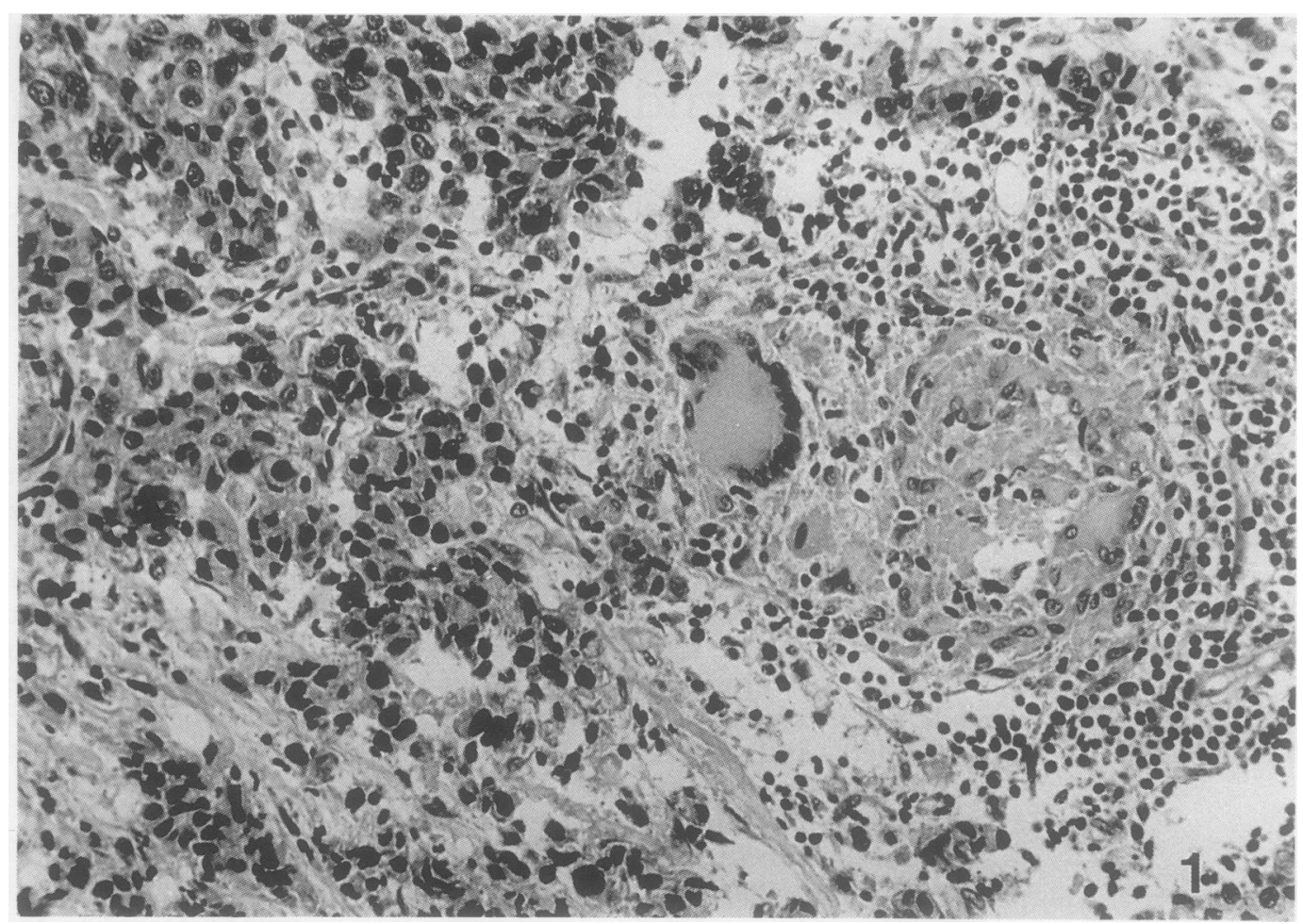

staining was positive; elastic fibres were unreactive. Immunohistochemically, antiserum against amyloid $\mathbf{P}$ component showed diffuse positivity (fig 3 ; inset) in the stroma and was haphazardly intermixed between carcinomatous elements and the granulomatous reaction. Beta 2 microglobulin was negative; anti-macrophage reacted with histiocytes; and a polyclonality of lymphocytic infiltrate was shown.

Electron microscopical examination showed that the neoplastic cells were oval and plump with bullous cytoplasmic extensions that were

frequently joined by attenuated desmosomes (fig 2). Nuclei showed deep clefts, contained finely dispersed chromatin, and one or two inconspicuous nucleoli. The cytoplasm contained numerous mitochondria, short strands of rough endoplasmic reticulum, scattered electron dense lysosomes and a few lipid droplets. No basal lamina was observed at the periphery of tumour cells. Giant cells showed irregular outlines and had abundant cytoplasm. Mitochondria were numerous and frequently contained large matriceal densities. Interestingly, the extracellular matrix focally
Figure 2 Transmission electron microscopy. Small groups of tumour cells surrounded by a fibrillar extracellular matrix. Note the presence of abundant mithocondria, lipid inclusions, and blunt cytoplasmic processes. Inset: attenuated desmosomes.

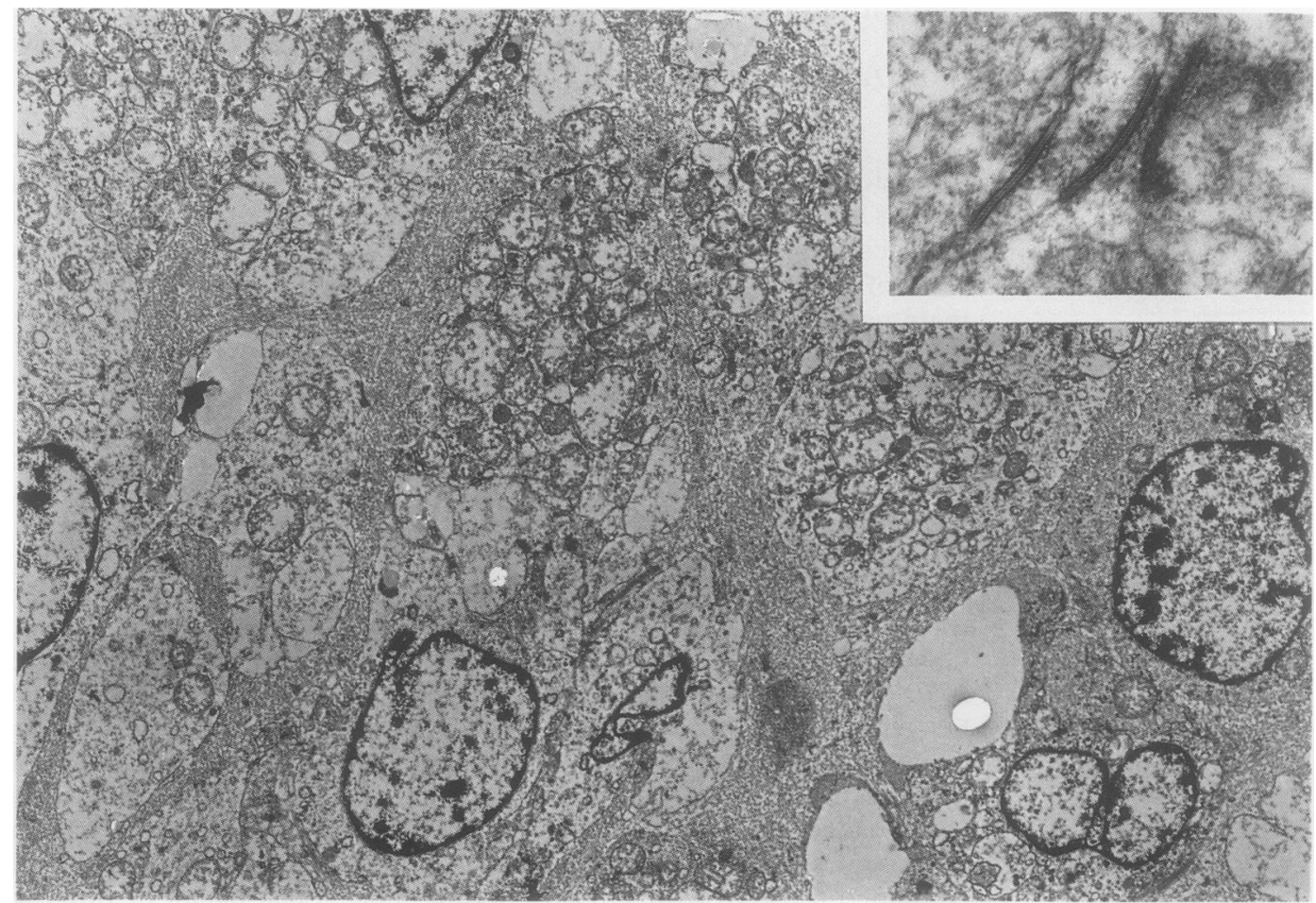


Figure 3 Detail of matrix showing a collection of gently curving tubules having a continuous beaded periodicity. Inset: Amyloid P component positivity

(immunoperoxidase).

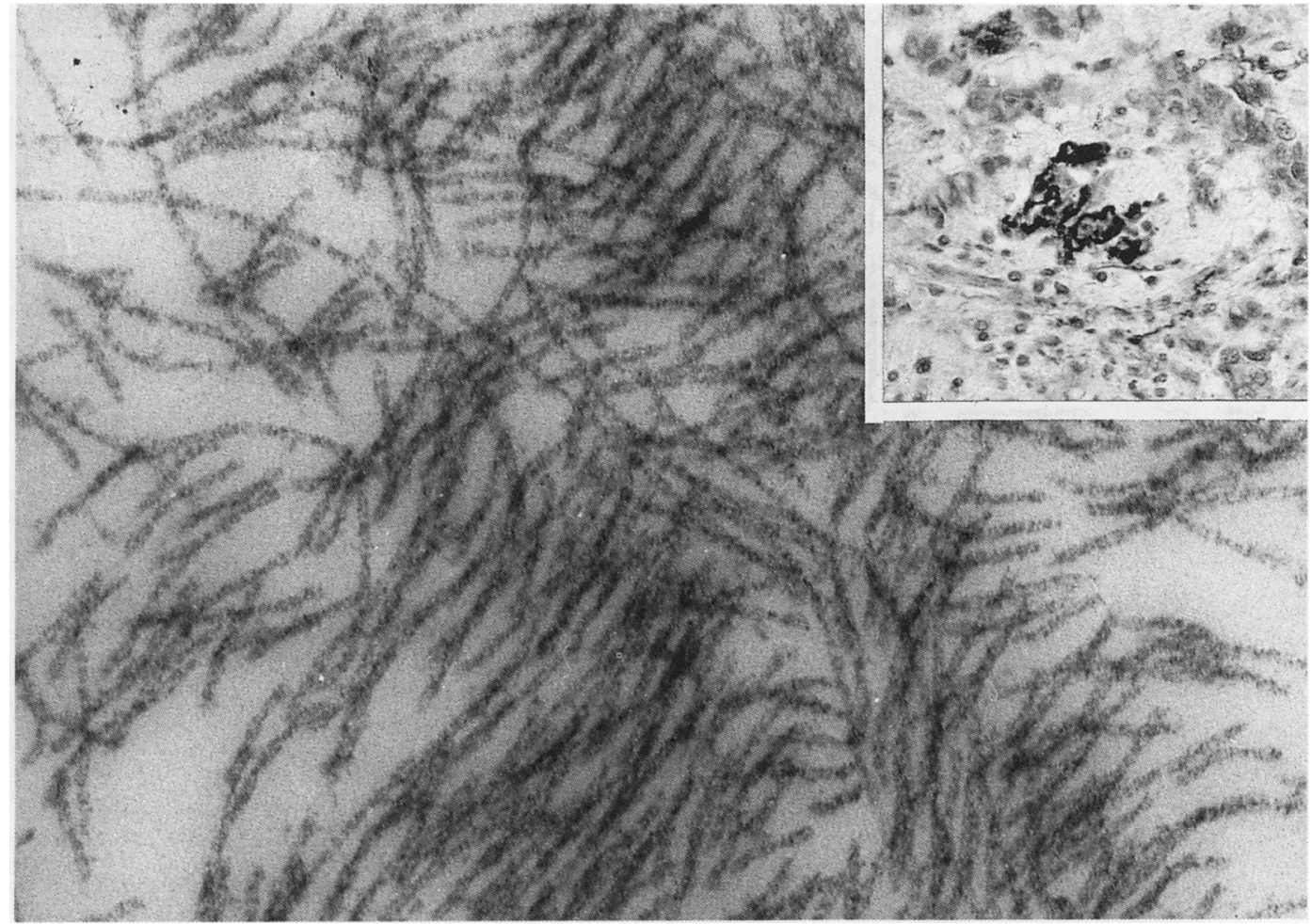

contained a mesh of non-branching, gently curving fibrils ranging from $10-13 \mathrm{~nm}$ in diameter, having a continuous beaded periodicity (fig 3). Cross sectioned fibrils looked as if they had hollow profiles and were closely juxtaposed at right angles to the cell membrane. No amorphous elastic tissue was observed. Collagen fibrils were detected in the fibrillar matrix.

\section{Discussion}

The presence of a granulomatous reaction with giant cells of Langhans' type and associated with invasive carcinoma of the breast has been reported only by Oberman in $1987 .^{1}$ In fact, previous reports have concentrated mostly on two different features: granulomas in axillary lymph nodes draining a breast carcinoma and stromal giant cells, predominantly of an osteoclast-like pattern, in mammary carcinoma. ${ }^{7-11}$ Conversely, the Langhans' type giant cells seen in our case do not belong to either of these groups. Giant cells detected in our case also clearly differ from the stromal giant cells described by Rosen, ${ }^{7}$ and Martinelli, ${ }^{12}$ exhibiting hypercromatic nuclei and megacaryocytic features, respectively. Moreover, all the cases reported above except for Oberman's did not describe a granulomatous stromal reaction.

The observation of a giant cell reaction in association with invasive carcinoma opens the question of whether the granulomas are induced by the neoplasm, or whether they should be considered in the context of systemic or local granulomatous disease. As far as the present case is concerned the latter possibility can be excluded.

It has been emphasised that granulomas like those here reported may represent a reaction to necrotic areas within the tumour. ${ }^{1}$ Although, microscopically, foci of necrosis were present in one case out of three reported by Oberman, ${ }^{1}$ necrosis was not present in our case.

Interestingly, our ultrastructural investigation showed an extracellular matrix much in fibrils consisting of variously arranged slender fibrils, $10-13 \mathrm{~nm}$ in diameter, characterised in cross-sections by hollow profiles. Fibrils of this nature correspond to the tubular amyloid recently described by Bourgeois et $a l^{13}$ in a kidney biopsy specimen and in medullary thyroid carcinoma. In both of these cases the amyloid deposits produced surprising reactions to the routine histochemical dyes (Congo red positive, thioflavin $B$ negative) thus suggesting a distinctive chemical composition for these deposits. However, the precise nature of these deposits is not currently understood.

Unlike the rarely reported amyloid tumour or amyloid deposition in breast tissue $e^{2-51415}$ showing amyloid exclusively around ducts and vessels along with foreign body giant cells, in the present case the tubular amyloid was scattered haphazardly. Moreover, this was positive both to Congo red stain and amyloid $P$ component. The demonstration of amyloid $P$ component in oxytalan fibres suggests that they are involved in elastogenesis. ${ }^{16-18}$ This would not be so in the case reported here because of the lack of cellular synthetic activity on electron microscopical examination as well as the association with Congo red positivity. Moreover, the oxytalan fibres have also been described in tissues which do not contain or produce elastin. ${ }^{19}$ There may therefore be an association between amyloid $\mathrm{P}$ component and tubular amyloid in the present case. This leads us to speculate whether specifically sensitised cytotoxic host $T$ cells react against tumour cells. Consequently, tubular amyloid could be associated with an abnormal immunological response. Unfortunately, in Oberman's series both electron microscopic investigation and 
specific stains to detect amyloid were not carried out so this association could not be confirmed.

It is our intention to follow up this patient to appraise if this unusual host reaction can modify the prognosis of primitive carcinoma, or is only, as suggested by Oberman, ${ }^{1}$ a rare morphological variant of breast cancer.

We thank Dr G Mazzoleni for his cooperation, Mr A Busi for his photographic work, and Mrs R Baroni for her expert technical help.

1 Oberman HA. Invasive carcinoma of the breast with granulomatous response. Am 7 Clin Pathol 1987; 8ranuloma

2 Fernandez BB, Hernandez FJ. Amyloid tumor of the breast. Arch Pathol 1975;95:102-5.

3 Lipper S, Khan LB. Amyloid tumor. A clinicopathologic study of four cases. Am $\mathcal{F}$ Surg Pathol 1978;2:141-5.

$4 \mathrm{Lew} \mathrm{W}$, Seymour A. Primary amyloid tumor of the breast. Case reports and literature review. Acta Cytol 1985; 29:7-11.

5 Silverman JF, Dabb DJ, Norris HT, Pories WJ, Legier J, Kay S. Localized primary (AL) amyloid tumor of the breast. Cytologic, histologic, immunocytochemical and ultrastructural observations. Am $\mathcal{f}$ Surg Pathol 1986;10: 539-45.

6 World Health Organization. Histological typing of breast tumours. Tumori 1982;68:191-8.

7 Rosen PP. Multinucleated mammary stromal giant cells: A benign lesion that simulates invasive carcinoma. Cancer
1979;44:1305-8.

8 Agnantis NT, Rosen PP. Mammary carcinoma with osteoclast-like giant cells: A study of eight cases with follow-up data. Am 7 Clin Pathol 1979;72:383-9.

9 Holland R, Van Haelst UJGM. Mammary carcinoma with osteoclast-like giant cells: additional observations on six osteoclast-like giant cells: addition
cases. Cancer 1984;53:1963-73.

10 Nielsen BB, Kiaer HW. Carcinoma of the breast with stromal multinucleated giant cells. Histopathology 1985; 9:183-93.

11 Tavassoli FA, Norris HJ. Breast carcinoma with osteoclast like giant cells. Arch Pathol Lab Med 1986;110:636-9.

12 Martinelli GN, Santini D, Bazzocchi F, Pileri S, Casanova S. Myeloid metaplasia of the breast. A lesion which clinically mimics carcinoma. Virchows Arch (Pathol Anat) 1983;401:203-7.

13 Bourgeois N, Buyssens N, Goovaerts G. Case for the Panel. Ultrastructural appearance of Amyloid. Ultrastruct Pathol 1987;11:67-76.

14 Hardy TJ, Myerowitz RL, Bender BL. Diffuse parenchymal amyloidosis of lungs and breast: its association with amyloidosis of lungs and breast: its association with diffuse plasmocytosis and $\mathrm{K}$-cha

15 Isobe T, Osseman EG. Patters of amyloidosis and their association with plasma cells dyscrasia, monoclonal immunoglobulins and Bence-Jones proteins. $N$ Engl $\mathcal{f}$ Med 1974;290:473-7.

16 Breathnach SM, Melrose SM, Bhogal B, et al. Amyloid-P component is located on elastic fibre microfibrils in normal human tissue. Nature 1981;293:652-8.

17 Inoue S, Leblond CP. The microfibrils of connective tissue: I. Ultrastructure. $A m \mathcal{F}$ Anat 1986;176:121-38.

18 Inoue S, Leblond CP, Grant DS, Rico P, The microfibrils of connective tissue: II. Immunohistochemical detection of the Amyloid $\mathrm{P}$ component. Am $f$ Anat 1986;176: the Amy

19 Ghadially FN. Extracellular matrix (extracellular components). In: Ultrastructural pathology of the cell and matrix. 3rd edn. London: Butterworths, 1988:1252-9. 